\title{
Aprendizagem narrativa no contexto do Estágio Supervisionado na Educação Infantil: reflexos na formação inicial docente
}

Joelson de Sousa MORAIS

Maria Divina Ferreira LIMA²

\begin{abstract}
Resumo
Neste artigo, de abordagem qualitativa do tipo narrativa (auto)biográfica, trazemos como objetivo: relacionar as tessituras da aprendizagem narrativa de estudantes do curso de Licenciatura em Pedagogia com o Estágio Supervisionado na Educação Infantil. Trata-se de uma pesquisa realizada com 06 (seis) estudantes estagiárias do curso de Pedagogia de uma universidade pública do Piauí, que desenvolveram o Estágio Supervisionado em Educação Infantil em 03 (três) Centros Municipais de Educação Infantil em Teresina - PI no ano de 2017. Os dispositivos metodológicos utilizados foram: observações, narrativas escritas e diário de pesquisa. Os resultados elucidam que a aprendizagem narrativa na formação inicial docente representa uma reflexividade (auto)formadora como dimensão emancipatória na pesquisa, no ensino e na formação inicial docente.
\end{abstract}

Palavras-chave: Educação da infância. Experiência do Estágio. Formação docente. Narrativas (auto)biográficas. Curso de Pedagogia.

\footnotetext{
${ }^{1}$ Doutorando em Educação pela Universidade Estadual de Campinas (UNICAMP). Mestre em Educação pela Universidade Federal do Rio Grande do Norte (UFRN). Pedagogo e Professor Substituto da Universidade Federal do Maranhão (UFMA)/Campus Codó MA. ORCID: https://orcid.org/0000-0003-1893-1316

E-mail: joelsonmorais@hotmail.com

2 Doutora em Educação pela Universidade Federal do Rio Grande do Norte (UFRN). Professora no Departamento de Métodos e Técnicas de Ensino (DMTE) da Universidade Federal do Piauí (UFPI), no curso de Pedagogia, e Professora Permanente no Programa de Pós-Graduação em Educação (PPGED/UFPI). ORCID: https://orcid.org/0000-0002-4552-6802

E-mail: lima.divina@gmail.com
} 


\title{
Narrative learning in the context of the supervised internship in childhood education: reflections in initial teaching training
}

\author{
Joelson de Sousa MORAIS
}

Maria Divina Ferreira LIMA

\begin{abstract}
In this article, with an (auto)biographical narrative-type qualitative approach, the objective is: to relate the textures of the narrative learning of students from the Degree in Pedagogy course with the Supervised Internship in Early Childhood Education. This is an investigation carried out with 06 (six) trainee students from the Pedagogy course at a public university in Piauí, who developed the Supervised Child Education in 03 (three) Municipal Centers for Early Childhood Education in Teresina-PI, in 2017. The methodological devices used were: observations, written narratives and research journal. The results clarify that narrative learning in initial teacher education represents a (self) formative reflexivity as an emancipatory dimension in research, teaching and initial teacher education.
\end{abstract}

Keywords: Childhood education. Internship Experience. Teacher training. (Auto)biographical narratives. Pedagogy course. 


\title{
Aprendizaje narrativo en el contexto de la práctica supervisada en educación infantil: reflexiones en la formación inicial de enseñanza
}

Joelson de Sousa MORAIS

Maria Divina Ferreira LIMA

\begin{abstract}
Resumen
En este artículo, con un enfoque cualitativo de tipo narrativo (auto) biográfico, el objetivo es: relacionar las texturas del aprendizaje narrativo de los estudiantes de la carrera de Grado en Pedagogía con el Pasantía Supervisada en Educación Infantil. Esta es una investigación realizada con 06 (seis) estudiantes internos en el curso de Pedagogía en una universidad pública en Piauí, quienes desarrollaron la Pasantía Supervisada en Educación Infantil en 03 (tres) Centros Municipales de Educación Infantil en Teresina - PI en el año 2017. Los dispositivos metodológicos utilizados fueron: observaciones, narraciones escritas y diario de investigación. Los resultados aclaran que el aprendizaje narrativo en la formación inicial del profesorado representa una (auto) formación reflexiva como una dimensión emancipadora en la investigación, la enseñanza y la formación inicial del profesorado.
\end{abstract}

Palabras clave: Educación Infantil. Experiencia de pasantia. Formación de profesores. Narrativas (auto) biográficas. Curso de Pedagogía. 


\section{Introdução}

O presente texto pontua algumas discussões acerca do aprendizado narrativo tecido por estudantes do curso de Pedagogia no contexto do Estágio Supervisionado na Educação Infantil no processo de formação inicial docente na licenciatura.

Por meio deste trabalho, buscamos trazer algumas reflexões, aprendizados e conhecimentos construídos como professores formadores nos cursos de licenciaturas da Universidade Federal do Piauí (UFPI), com ênfase nas disciplinas de estágios no curso de Pedagogia em que temos desenvolvido a supervisão com os estudantes estagiários em acompanhamento que realizamos no contexto das escolas de Educação Infantil.

Trata-se, portanto, de uma pesquisa qualitativa na abordagem da pesquisa-formação ${ }^{3}$ narrativa (auto)biográfica em educação como uma perspectiva que busca dar visibilidade à subjetividade dos sujeitos a partir dos saberes e fazeres que tecem narrativamente dos processos reflexivos, formativos e de aprendizagem construídos cotidianamente.

Ancorada em Josso (2010), a pesquisa-formação significa um modo de inseparabilidade entre os processos de pesquisar e se formar, uma vez que os sujeitos envolvidos nas pesquisas, em relação com os participantes do estudo, passam por reflexões e tomadas de consciência, transformando-se e se formando durante os percursos trilhados.

Inventariamos outras tantas palavras neste texto, as quais são um modo de escolha que fazemos, pelo fato de que “[...] somos viventes com palavras, elas nos fazem, nós a fazemos e, nesse movimento, (re)construímos o mundo” (BRAGANÇA, 2018, p. 66).

Damos primazia a uma experiência de pesquisa realizada no segundo semestre do ano de 2017, da qual, embora tenha envolvido um maior número de participantes, selecionamos 06 (seis) estudantes estagiárias do curso de Pedagogia que estavam cursando a disciplina e desenvolvendo atividades no Estágio Supervisionado na Educação Infantil em 03 (três) Centros Municipais de Educação Infantil (CEMEIs) pertencentes à rede pública municipal de Teresina - PI.

Os objetivos deste artigo buscam relacionar as tessituras da aprendizagem narrativa de estudantes do curso de licenciatura em Pedagogia com o Estágio Supervisionado na Educação Infantil

\footnotetext{
${ }^{3}$ Usamos essa forma de escrita por uma escolha política, teórico-epistemológica e metodológica no contexto da abordagem narrativa (auto)biográfica e com a qual aprendemos com os estudiosos do cotidiano à luz de Alves (2003) e Oliveira (2012). A junção de duas ou mais palavras tem um sentido de fazer uma invenção outra de significados, contrapondo-se à lógica clássica da ciência positivista. Neste texto, primamos por essa forma de escrita, destacando palavras em itálico com esse sentido.
} 
e mostrar como acontecem as aprendizagens narrativas construídas no Estágio Supervisionado na Educação Infantil no processo de formação inicial docente de estudantes de Pedagogia.

A questão de partida que nos impulsiona pensar nesse texto é: quais as implicações da aprendizagem narrativa no processo de formação inicial docente de estudantes no curso de Pedagogia mediado pelo Estágio Supervisionado na Educação Infantil?

Ao invocarmos uma tematização acerca da aprendizagem, percebemos que várias discussões se amparam no âmbito da psicologia, muitas das quais desenvolvidas no contexto da psicologia experimental, o que não é o propósito deste texto, pois fazemos uma reflexão que situam as teses educacionais pela abordagem narrativa (auto)biográfica em educação, dando centralidade ao aprender tecido pelos sujeitos em suas relações produzidas com os tantos outros que os constituem e conseguem materializar, narrativamente, em suas escritas, as reflexões que constroem nos percursos e itinerários formativos trilhados. Nesse sentido, compreendemos que

[...] a aprendizagem consiste na aquisição, por um ser vivo, de comportamentos novos que não fazem parte do repertório do poder-fazer ou habilidades herdados, geneticamente programadas, ou dependentes da epigênese cortical (RICOEUR, 2007, p. 73).

A perspectiva da aprendizagem narrativa, que concebemos neste escrito, está subjacente às ideias de Goodson (2019, p. 282), segundo o qual

está “[...] presente na elaboração e manutenção continuada de uma narrativa de vida ou de identidade”.

Além de ser uma expressão cunhada por Goodson (2019), a aprendizagem narrativa é tematizada pelo autor à luz das reflexões produzidas pelos sujeitos nos processos de desenvolvimento profissional e entremeada pelos currículos, saberes e experiências pelas quais cada pessoa passa, desenvolve ou constrói ao longo da vida.

A fundamentação teórico-metodológica e epistemológica na qual está pautada este texto se consubstancia pelos contributos da abordagem narrativa (auto)biográfica em: Josso (2010), Ricoeur (2007; 2010) e Goodson (2019); na perspectiva do estágio supervisionado em: Almeida; Pimenta (2014); e nos sentidos da linguagem dos sujeitos à luz de Bakhtin (2017), entre outros autores.

Contrários ao aligeiramento da formação docente e valorizando o tempo benjaminiano (BENJAMIN 2012), no sentido de um dimensão artística, sensível e estética da narrativa tecida à luz 
das implicações geradas pelos estudantes das licenciaturas como narradores e experienciadores de suas vivências, defendemos, neste trabalho, a centralidade do aprendizado narrativo como uma perspectiva outra de emancipação das consciências e transformação dos sujeitos pela narratividade, conforme será aludido nas linhas que se seguem.

\section{Potencialidades da pesquisa-formação narrativa (auto)biográfica e os itinerários trilhados}

Nos percursos da pesquisa científica, inúmeras escolhas são feitas e reflexões tecidas pelos pesquisadores ao longo das vivências e experiências entre o processo de pesquisar e as questões relacionadas ao objeto de estudo ou dimensão contextual - em que se tece a construção do conhecimento, dos dispositivos metodológicos e da abordagem aos sujeitos participantes do estudo para que possam ser concretizadas todas as etapas da pesquisa e, assim, os objetivos sejam alcançados.

Em se tratando da pesquisa-formação ${ }^{4}$, termo cunhado pelos estudiosos do movimento da corrente de histórias de vida em formação, que iniciou seus estudos e práticas na formação de adultos nos inícios da década de 1980 nos países francófonos, mais precisamente na Universidade de Genebra (Suíça) e na Universidade de Montreal (Canadá), sendo uma de suas fundadoras Josso (2010), compreendemos que essa abordagem tem o significado de um processo formativo pela tomada de consciência, por parte do sujeito, dos percursos trilhados ao longo da pesquisa, o que possibilita uma (auto)formação à medida em que tece reflexões desse processo, gerando mudanças substanciais e permitindo a construção de saberes, conhecimentos e aprendizagens pela experiência construída paulatinamente, em partilha.

Na pesquisa-formação, a produção do conhecimento científico se dá com abertura ao diálogo e trocas contínuas de saberes, conhecimentos e experiências entre os sujeitos envolvidos no processo, afinal trata-se de uma proposta que se inscreve como “[...] metodologias dialógicas entre o pesquisador e os sujeitos pesquisados, principalmente, por compreender que, nesse processo, a formação acontece em partilha, para ambos” (MOTTA; BRAGANÇA, 2019, p. 1038).

\footnotetext{
${ }^{4}$ Vale ressaltar que Josso (2010) usa o termo pesquisa-formação separado por hífen. Neste texto, primamos pelo uso de uma única palavra sem o hífen pelas razões que já expomos anteriormente, por comungarmos por uma forma de escrita outra, pautados pelos estudiosos nos/dos/com os cotidianos, a exemplo de Nilda Alves (2003).
} 
No que se refere à proposta deste estudo, realizamos o acompanhamento em pesquisaformação com 06 (seis) estudantes do curso de Pedagogia durante o Estágio Supervisionado em Educação Infantil, no segundo semestre do ano de 2017, mediado por encontros que aconteceram em articulação com a Universidade e as escolas públicas municipais de Teresina - PI, que foram ao todo 03 (três) CMEIs.

Utilizamos como dispositivos metodológicos na produção do conhecimento científico que resultou neste artigo: observações, diário de pesquisa e escritas narrativas, explicitados a seguir a nível de procedimentos desenvolvidos ao longo do processo.

As observações foram realizadas por nós, como professores pesquisadores formadores, durante os encontros que realizamos presencialmente, principalmente, no cotidiano das escolas infantis, dando centralidade ao que conseguimos captar dos saberes, fazeres e aprendizados que pudessem construir as estudantes estagiárias, participantes da pesquisa, consubstanciados pelas narrativas escritas em seus diários, que eram, inclusive, compartilhados conosco ao longo do processo do qual íamos participando.

O diário foi um dos dispositivos metodológicos que tanto nós produzimos, como professores pesquisadores, quanto as participantes do estudo elaboraram, como forma de registro essencial de nossas aprendizagens e conhecimentos construídos em articulação com o que observávamos no estágio e da relação tecida com as professoras titulares e auxiliares, em articulações com as crianças na escola e na sala de aula.

A narrativa escrita se tornou um modo privilegiado de dizerfazerdizer ${ }^{5}$ os saberes da formação inicial docente, evocados narrativamente pelas estudantes estagiárias do curso de Pedagogia, participantes do estudo, já que, por meio desse dispositivo, passaram a refletir sobre os percursos trilhados e a tecer dimensões formativas desses encontros na perspectiva temporal do narrado, isso também se deu conosco, como professores formadores pesquisadores.

Circunscrita, portanto, em um tempo, em um determinado lugar e com sujeitos específicos com os quais compartilham a formação e o aprendizado, ganhando força, a narrativa escrita

constitui um suporte particularmente adequado para a pesquisa dos processos de formação e de conhecimento, porque dá acesso tanto às partes que a compõem como

\footnotetext{
${ }^{5}$ Aprendemos essa expressão com Motta; Bragança (2019), que a trazem e tematizam a pesquisa-formação narrativa (auto)biográfica com professoras da Educação Infantil na relação com as crianças. Situamo-la no contexto deste trabalho estabelecendo relação com a aprendizagem narrativa de adultos em formação inicial docente.
} 
a um conjunto a que foi atribuído um título. Além disso, porque contém simultaneamente o fatual e o pré-interpretado (JOSSO, 2010, p. 215).

Nesse sentido, registrar por escrito narrativamente a experiência do sujeito dá condições de si perceber nesse processo à luz de uma (auto)formação como uma dimensão balizadora que se consolida em um movimento que vai do plano do pensamento ao plano da ação, dando, assim, visibilidade aos saberes e aos conhecimentos que são possíveis de construir, (re)atualizar e significar no processo formativo inicializado.

Por uma questão de ética na pesquisa científica, não iremos revelar os nomes verdadeiros das participantes em função das escolhas que fizemos para respeitar as suas identidades. Assim, adotamos pseudônimos para nos reportar a elas, assim designadas: Larissa \& Marília; Fabiana \& Milena; Luana \& Karina.

Quanto ao perfil das pesquisadas, foram 06 (seis) estudantes do sexo feminino, situando-se numa faixa etária entre 18 a 24 anos. A escolha pela participação de mulheres tem a ver com o fato de que o curso de Pedagogia é composto, em sua maioria, pelo sexo feminino, tendo em vista a atratividade da carreira docente, historicamente e em maior proporção, por esse gênero.

O uso das narrativas das participantes da pesquisa foi autorizado por elas, e isso foi acordado entre alunas e professores no início do estudo, etapa em que foram esclarecidos os propósitos da pesquisa-formação e a possibilidade de que as fontes narrativas pudessem ser utilizadas e publicizadas em meios de divulgação científica, eventos ou outras atividades de ensino, educação, pesquisa e desenvolvimento profissional.

Em termos específicos, vale ressaltar que as narrativas escritas foram produzidas pelas participantes da pesquisa em seus diários, fruto dos encontros do Estágio Supervisionado na Educação Infantil, mediado por observações e regências que as alunas desenvolveram, em decorrência da proposta que, como professores pesquisadores, fizemos a elas no início das aulas que tivemos no começo do segundo semestre letivo do ano de 2017.

Como já temos uma prática de ensino, pesquisa e formação que são entrelaçadas em nossos itinerários percorridos, esclarecemos para as discentes que suas narrativas tanto iriam resultar no que, naquele momento, chamamos de "relatório final da disciplina”, para ser avaliado e atribuída nota, como, sobretudo, numa proposta de pesquisa direcionada à produção de um artigo a ser publicado posteriormente. Tudo isso acordado, tivemos o aceite e a conivência das participantes do estudo para publicização de suas narrativas. 
Neste artigo, apresentamos apenas alguns trechos das narrativas das estudantes estagiárias do curso de Pedagogia que fizeram parte da pesquisa-formação. Muito do que produziram narrativamente em seus diários foi transposto para o relatório final da disciplina, e algumas partes compuseram o banner que elaboraram para apresentar em um seminário, no final do semestre letivo, que foi avaliado por nós professores formadores pesquisadores e por demais professores de outras turmas de estágio da instituição, evento que intercambiou experiências, aprendizados e construção de conhecimentos acerca do vivido, praticado e desenvolvido pelos estudantes e docentes envolvidos.

Para o processo de interpretação e compreensão das narrativas das participantes da pesquisa, invocamos o círculo hermenêutico da narratividade e da temporalidade, em Ricoeur (2010), uma vez que os sentidos não são dados, mas significados no plano da linguagem, da interpretação e do refletido pelos sujeitos envolvidos com a narrativa apresentada, dando outros tantos sentidos, como nos faz pensar Bakhtin (2017).

Assim, reforçamos que “[...] a compreensão, mesmo a compreensão de um outro singular na vida cotidiana, nunca é uma intuição direta e sim uma reconstrução” (RICOEUR, 2010, p. 161).

Interpretar e compreender as narrativas é, pois, uma perspectiva que se dá em um determinado tempo, em um contexto singular e com pessoas específicas que fazem parte do que estamos realizando e desenvolvendo, o que se torna essencial e imprescindível no âmbito da pesquisa e na construção do conhecimento científico.

As narrativas das participantes da pesquisa, que serão apresentadas a seguir, foram produzidas em dupla com a qual foram tecidas algumas

discussões e reflexões acerca de suas aprendizagens formadoras, o que ocorreu tanto nas escolas como na Universidade.

\section{O Estágio Supervisionado na Educação Infantil mediado pela aprendizagem narrativa em formação inicial docente}

O estágio supervisionado permite a realização de um voo compreensivo e reflexivo dos sujeitos pela cultura escolar, pelas dinâmicas em que os praticantes do cotidiano (OLIVEIRA, 2012) se lançam e pelas relações estabelecidas entre crianças, professoras e entorno da escola.

Entre muitos desafios, saberes e conhecimentos a aprender e ensinar, a formação inicial docente vai se compondo à medida que passamos a aliar as abordagens teóricas, históricas, políticas e metodológicas e de tantas outras vertentes no processo formativo, que se potencializam na relação 
teoriaprática, na qual os sujeitos percebem e constroem, durante os contatos com as escolas e as reflexões tecidas na academia, e outras tantas questões latentes essenciais à formação para o exercício profissional da docência quando estiverem atuando no ofício do magistério.

Pensar o Estágio Supervisionado na Educação Infantil como formadores de professores é situarmo-nos, responsavelmente, numa preocupação relacionada ao perfil de professor que queremos formar, para qual sociedade e para qual educação, já que esses sujeitos estarão formando outras pessoas e contribuindo com a tessitura social, econômica, política e cultural em que se inserem.

Nesse sentido, ser professor de estágio implica empreendermos um projeto, acima de tudo, responsável, ético e compromissado com a formação de futuros professores que estarão atuando profissionalmente. Assim, vale considerarmos os modos de realização do nosso trabalho, na mobilização de reflexões e discussões imprescindíveis ao processo formativo inicial e que poderão contribuir potencialmente com o saber e o fazer docente.

A compreensão que temos de estágio é um processo formativo intensivo, em que o sujeito constrói crenças, saberes e conhecimentos das dinâmicas de atuação da docência à luz do que desenvolvem os professores no cotidiano escolar, passando a compreender as múltiplas questões que envolvem o ser professor, a cultura da escola, a organização e desenvolvimento do trabalho pedagógico e tantas outras sensibilidades, percepções e destrezas que se relacionam aos processos educativos no aprender, educar e ensinar.

Essa compreensão está subjacente ao que desenvolvemos e realizamos como professores nos cursos de licenciaturas, com ênfase para o Estágio Supervisionado na Educação Infantil no curso de Pedagogia, considerando a singularidade e a especificidade que evolvem essa etapa de ensino.

Ao refletirmos por esse prisma, acreditamos que nos aproximamos das reflexões pontuadas pela literatura acerca do estágio, nas quais são elucidadas caracterizações e aspectos conceituais, conforme a seguinte proposição:

[...] entendemos o estágio como um campo de conhecimento que envolve estudos, análise, problematização, reflexão e proposição de soluções para o ensinar e aprender, e que compreende a reflexão sobre as práticas pedagógicas, o trabalho docente e as práticas institucionais, situados em contextos sociais, históricos e culturais (ALMEIDA; PIMENTA, 2014, p. 29).

Esse propósito nos incita a elucidarmos os efeitos formativos, reflexivos e transformadores que o Estágio Supervisionado traz e permite construir, com os sujeitos, no contexto de formação inicial para a docência. 
No que se refere à Educação Infantil, cabe pensarmos na especificidade que configura essa etapa de ensino, tendo em vista que é o momento em que a criança vai ter o primeiro contato com o processo de escolarização e o período que envolve uma complexa perspectiva de formação de sua personalidade, envolvendo aspectos sociais, culturais, relacionais e no âmbito da sua cognição, relevantes para a sua aprendizagem. Nesse contexto, não podem ser desconsiderados os meios de socialização e as interações criadas no mundo à volta da criança e com as pessoas que

compartilham, junto com ela, o seu cotidiano em vários contextos e realidades.

Por isso, torna-se fundamental pensarmos como se tece a formação inicial do docente que lidará com esse público e com essa realidade, requerendo um olhar sensível, atento e de constantes reflexões construídas, pois o professor, pautado na responsabilidade, precisa tomar decisões e mobilizar saberes e fazeres que envolvem a criança, seus familiares e todos os sujeitos com os quais ela convive.

Pensando na qualidade do processo de formação inicial de professores de infância, em que se situa o curso de Pedagogia, trazemos à luz alguns saberes e fazeres que permeiam a prática pedagógica de professores de crianças de zero a cinco anos, e que consideramos necessários às demandas emergentes do trabalho docente nessa etapa de ensino e educação, quais sejam:

Aliar cuidado e educação; planejar experiências diversificadas, que atendam aos vários aspectos do desenvolvimento infantil; estabelecer e manter uma relação cooperativa e amistosa com as famílias; aprender a ser parceiro no desenvolvimento infantil, estimulando-o, mas não o apressando; abordar as diferentes áreas de conhecimento de maneira integrada; vincular a aquisição de novos conhecimentos e habilidades pelas crianças aos seus reais desejos e necessidades, promovendo uma verdadeira aprendizagem significativa; dar atenção individualizada às crianças; dar atenção privilegiada aos aspectos emocionais, especialmente durante o período de adaptação à creche ou pré-escola; dar oportunidade e estímulo para a criança expressar os seus sentimentos, desenvolver a sua autonomia, a sua curiosidade, imaginação, capacidade de expressão e autonomia, ajudando-a a desenvolver a sua identidade cultural, racial e religiosa (CRUZ, 2010, p. 356).

Esses são apenas alguns dos conhecimentos, saberes e práticas que poderiam ser considerados e mobilizados tendo em vista a necessidade de desenvolver um trabalho de atuação profissional significativa e valorosa com as crianças na Educação Infantil. Por isso, é importante refletirmos sobre a formação inicial e o caráter desafiante e fundamental de tecermos constantes 
debates, problematizações e casos de ensino pautados em situações diversas, que podem se situar entre aqueles relacionados às problemáticas variadas do contexto de ensino e as que surgem no âmbito de possibilidades concretas do trabalho docente e que, por ventura, poderiam ser enfrentados pelos futuros professores. Dessa forma, acreditamos impulsionar reflexões constantes e (re)direcionamento de saberes e fazeres e de outras questões que emergem durante a realização do Estágio Supervisionado nessa etapa de ensino.

Convém salientarmos que quanto mais questões emblemáticas e pautadas na realidade escolar do professor de infância forem debatidas no processo de formação inicial, maiores serão as contribuições trazidas aos sujeitos nesse processo, os quais constituirão, com mais propriedade, dispositivos potentes e dinamizadores dos percursos de desenvolvimento profissional da docência quando se inserirem no contexto de trabalho.

Uma das narrativas de duas estudantes de Pedagogia, participantes da pesquisa, revelou a contribuição que o curso está oferecendo em suas formações, conseguindo perceber as implicações desse processo, fruto da relação teoria-prática:

O Estágio Supervisionado é um dos momentos mais importantes da vida de um acadêmico em formação, pois um dos objetivos é estabelecer um primeiro contato com o campo de atuação e assim viabilizar articulações entre a teoria e a prática. Vivenciar a docência é de certa forma refletir sobre ser professor, pensamos sobre essa outra dimensão ou contexto que alguns acadêmicos só ouviram falar (Narrativa das estudantes Larissa \& Marília, 2017).

As estudantes conseguem externar algumas reflexões propiciadas pela realização do estágio na escola, lócus das atividades desenvolvidas por elas em suas inserções formativas.

Ao materializar os pensamentos que estavam ainda no plano das ideias, e passaram a figurar na narrativa escrita produzida pelas estudantes de Pedagogia, pensamos que o exercício desse processo caracterizou-se como substanciais na construção de uma reflexividade do que estão passando enquanto vivências e experiências formadoras que pontuam os acontecimentos tecidos em uma dimensão temporal do praticado, o que nos dá a entender que as participantes do estudo realizaram “[...] um trabalho de compreensão da experiência viva não repetível” (RICOEUR, 2010, p. 161).

Pensamos, ainda, que a experiência da aprendizagem narrativa, evocada e produzida pelas alunas estagiárias nos faz conversar com o que Abrahão (2016, p. 42) chama de reflexividade (auto)biográfica, que consiste em um processo em que “[...] cada sujeito possibilita expressar as 
próprias vivências em termos de experiências de vida e de formação, com a inclusiva construção identitária”.

O caráter singular do que cada sujeito constrói em função do vivido, praticado e experienciado ganha dimensões implicadoras e marcantes para a consolidação de aprendizagens fundamentais na formação inicial docente, que são consubstanciadas pelo contato diário com as crianças e as professoras das escolas.

O momento de inserção no cotidiano das escolas no início do estágio revelou-se como uma marca determinante na tessitura de saberes, fazeres e outros tantos modos de percepção do ser professora bem como dos conhecimentos relacionados à formação e à cultura institucional específica que demanda a Educação Infantil já que as relações estabelecidas com as crianças foram mobilizando reflexões, planejamento e discussões, tudo continuamente narrado pelas estudantes universitárias quando nos encontravam nas escolas (nos espaços em que era possível dialogarmos) e no âmbito da Universidade.

A narrativa de outras participantes do estudo refletiu um teor que se aproxima muito do que enunciaram as estudantes na narrativa anterior, colocando ênfase na preocupação que ora se apresenta muito fortemente nos cursos de formação de professores: a questão da teoria-prática. Isso se deu muito pelo contato direto com a escola e o desenvolvimento do trabalho pedagógico na Educação Infantil, como relataram as estudantes:

Este primeiro contato com a docência mostrou os problemas e desafios que o professor enfrenta em sala de

aula. Esta disciplina nos proporcionou fazer uma reflexão profunda sobre a teoria e a prática. Podemos perceber que as teorias que aprendemos durante o nosso percurso de formação é de suma importância para a prática, mas muitas vezes é preciso o professor usar de conhecimentos empíricos para solucionar problemas que vão surgindo no cotidiano escolar. O estágio curricular supervisionado nos proporciona construir uma prática docente, através da observação e da prática em sala de aula. (Narrativa das estudantes Fabiana \& Milena, 2017).

Diante do exposto, identificamos três movimentos e contextos ressaltados nas narrativas das estudantes estagiárias, quais sejam: 1) os que se inserem na formação universitária; 2) os relacionados à didática que as professoras desenvolvem no cotidiano da escola infantil; e 3) os que envolvem as relações e interações estabelecidas com as crianças como uma forma que suscita outras tantas possibilidades de (re)elaboração da prática pedagógica das professoras atuantes nesse segmento. $\mathrm{O}$ fato de serem repensadas e utilizadas outras práticas para além do que a 
realidade mostra tem sido uma tônica pautada nas necessidades que as crianças têm, o que implica mudança quanto ao saber e ao fazer professoral como também mobiliza outras dimensões reflexivas nas licenciandas.

A instituição educativa configura-se, portanto, como um lócus privilegiado de formação e aprendizagem profissional da docência por contribuir potencialmente para a construção de um perfil de ser professora a partir da vivência de uma realidade específica, pondo em xeque o que consegue depreender da docência e da cultura em que estão imersas. Afinal, “[...] a formação centrada na instituição educacional não é apenas uma estratégia de formação como conjunto de técnicas e procedimentos, mas tem uma carga ideológica, de valores, de atitudes, de crenças” (IMBERNÓN, 2016, p. 156).

A relação com o outro tem sido, portanto, foco de pensamentos, planejamentos e (re)orientação da prática educativa e pedagógica que enfrentam as professoras da Educação Infantil, e percebidas pelas estagiárias em contato cotidiano com essas docentes. Conseguimos notar essa questão tanto por meio de suas narrativas como em observações que tivemos com elas na rotina escolar, potencializadas por conversas que narravam esses acontecimentos. Isso nos remete a ideia de alteridade, retratada por Bakhtin (2017), segundo a qual o sujeito se permite passar por transformações, fruto das relações estabelecidas com os outros, que vão constituindo o seu eu e a sua subjetividade.

Mais uma vez, como podemos perceber, a relação teoria-prática foi uma das fortes dimensões que acompanharam as estudantes durante o estágio. Lançar-se em um universo em que muitas coisas vão acontecendo e sendo gestadas pelos movimentos entre professores regentes, crianças, estudantes e professores universitários vai imprimindo um aspecto singular à realidade em que acontece o estágio.

Posto isso, reforçamos que se trata de uma questão que se fortalece à medida que entendemos que há um contexto absolutamente diferente e específico que as próprias estudantes estão experienciando na formação inicial docente, pois estavam imersas em uma dada escola, com determinados sujeitos e não outros, em um tempo construído por elas em articulação com os demais sujeitos naquele contexto, pelas múltiplas relações que iam tecendo-se.

Fazer alusão (nas narrativas de aprendizagem ou aprendizagem narrativa) à ação de relacionar a teoria à prática e à ideia de que elas se retroalimentam continuamente nas reflexões cotidianas produzidas pelas estudantes estagiárias participantes da pesquisa é uma perspectiva que sempre vem nos acompanhando tanto no processo de formação de professores quanto no cotidiano 
da prática pedagógica nas escolas, reforçando o movimento de construção de saberes, de aprendizados e de conhecimentos.

Por isso, essas narrativas expressas anteriormente pelas estagiárias participantes da pesquisa nos põem a refletir acerca de que “[...] os saberes teóricos propositivos se articulam, pois, aos saberes da prática ao mesmo tempo ressignificando-os e sendo ressignificados” (ALMEIDA; PIMENTA, 2014, p. 20).

O aprender pela narrativa é, pois, uma das questões que se mostram contundentes e contribuidoras do processo de formação inicial, sobretudo quando o Estágio na Educação Infantil consegue ser construído a partir de uma multiplicidade de experiências formadoras, transformadoras e reflexivas, pondo em articulação os saberes teórico-práticos que circulam entre as escolas e a formação universitária.

Um terceiro grupo de estagiárias que fez parte da pesquisa-formação conseguiu evidenciar as diferentes características que o estágio apresenta em suas formações, trazendo, ainda, o papel da gestão escolar na relação

estabelecida com as professoras da Educação Infantil, como elucidam as estudantes em suas narrativas a seguir:

[...] evidenciamos que as experiências vivenciadas na disciplina de Estágio Supervisionado em Educação Infantil contribuíram de forma relevante para a nossa futura formação docente. Observar, auxiliar e ministrar aulas no CMEI em destaque permitiu a compreensão dessa área de atuação do pedagogo tão cheia de significados. Percebemos a complexidade que permeia este universo assim como os dilemas e as necessidades enfrentadas pela equipe docente e gestora. (Narrativa das estudantes Luana \& Karina, 2017).

Pelas narrativas elucidadas, salientamos três grandes conjuntos de atividades que se mostraram substanciais no desenvolvimento do estágio pelas estudantes: observar, auxiliar e ministrar aulas. São dimensões que alicerçam o estágio e contribuem para a (auto)formação das participantes do estudo e para nós também, como professores formadores, no sentido de conseguirmos aludir, em nossas narrativas (auto)biográficas, a uma reflexão tecida nesse processo formativo.

Pensando bakhtinianamente (BAKHTIN, 2017), tais questões, apesar de serem atinentes propriamente ao estágio, não têm os sentidos dados e, por isso, são construídos reflexivamente pelas 
estagiárias em relação conosco e com os tantos outros que, juntos, fomos partilhando a experiência do estágio

na medida em que passamos a nos debruçar sobre reflexões acerca da ação mobilizada entre a academia e as escolas infantis. O conceito de alteridade, portanto, acaba sendo central nas relações estabelecidas no estágio, tecidas pelas estudantes com os vários sujeitos que intercambiam conversas, saberes e aprendizados e se transformam, mutuamente por essas relações.

Vimos que o Estágio na Educação Infantil representa um contexto de reflexão que perpassa o observado e percebido pelas estudantes estagiárias, depreendendo-o como um cenário de trabalho no qual vai se inserir o pedagogo. Compreendemos que ele pode atuar em outras áreas, setores e etapas de ensino, o que é reforçado pela sua formação polivalente e de um currículo, que contempla várias áreas do saber, em consonância com o que preconizam as diretrizes curriculares da área e a legislação educacional que normativa o curso de Pedagogia no cenário brasileiro.

Diante das narrativas apresentadas pelas estudantes estagiárias do curso de Pedagogia, no desenvolvimento do Estágio Supervisionado na Educação Infantil, pudemos perceber o quanto a narrativa se torna um meio privilegiado para refletirem acerca dos percursos por elas trilhados, gerando contributos para a sua formação e nos propiciando outros tantos elementos e aspectos formativos como professores pesquisadores no contexto da abordagem narrativa (auto)biográfica.

De fato, notamos a centralidade da narrativa como uma perspectiva potencial em que os sujeitos se atualizam e constroem os saberes, experiências e conhecimentos do processo formativo e dos contextos de saberes e fazeres da profissão professor, alcançados pelas reflexões que fazem tomar consciência dos itinerários tecidos ao longo do tempo. Nesse contexto, tem-se, então, o caráter de formador e de (auto)formação propiciado pela narrativa. Sendo assim, refletimos que:

[...] narrativas propiciam e criam espaço para "momentos pedagógicos” nos quais as pessoas podem se conectar consigo mesmas, umas com as outras, com suas próprias cultura e tradição, com suas esperanças e aspirações e, em última instância, com uma construção de conhecimento intencional e orientada, que serve a suas trajetórias pessoais e públicas (GOODSON, 2019, p. 114).

Esse movimento de parar para pensar a ação e materializar narrativamente o aprendido constitui uma mola propulsora para transformações e construção de inúmeros conhecimentos da formação, da prática pedagógica e dos saberes necessários e relevantes ao ensino e à profissão de 
pedagogo, fatores que acompanham o sujeito ao longo da vida e que se tornam imprescindíveis para a consolidação do sucesso profissional.

A reflexão do que se faz ou intenciona fazer no contexto do estágio ou da atuação profissional docente é, portanto, um modo gerador de conscientização e aprendizagem do sujeito na transformação de um contexto, de si próprio e dos percursos formativos que tece no processo de formação inicial, no cotidiano do desenvolvimento profissional e por toda a vida laboral.

O entrelaçamento entre as várias atividades realizadas e pensadas, o que acontece na escola pública nos saberes e fazeres das professoras da Educação Infantil e de todos os agentes envolvidos nesse contexto e de que modo se representam, trazem às estagiárias em processo de formação inicial, uma dinâmica disparadora de reflexões que ganha notoriedade e visibilidade pela narrativa que registram em suas escritas. Nesse movimento de transpor as narrativas para o plano da escrita, as experiências e os conhecimentos vão sendo construídos.

Duas das estudantes das quais já trouxemos outras narrativas neste texto expressaram as provocações que o estágio conseguiu gerar nelas e o poder de (auto)reflexão promovido pela experiência, que consideramos uma das questões mais importantes do processo formativo inicial docente e que é uma prática cara e sensível de ser pensada e praticada no futuro profissional como professoras. Assim se posicionaram as estudantes acerca disso:

Durante a carga horária dedicada à observação, atribuímos sentido aos contextos vivenciados, o que nos provocou momento de autorreflexão da prática, mas especificamente, quais seriam as propostas pedagógicas

para a referida CMEI (Narrativa das estudantes Luana \& Karina, 2017).

Para além de um aspecto de cumprimento de uma matriz curricular e embasadas pelos princípios institucionais preconizados pela formação universitária, no Estágio Supervisionado na Educação Infantil, com as estudantes estagiárias passamos a discutir os múltiplos aspectos que perpassavam as interrelações estabelecidas entre uma instituição e outra. Muitas questões anteriores ao desenvolvimento do estágio foram colocadas como motivadoras para potencializarem seus processos formativos, como: a curiosidade e a expectativa, características da formação inicial docente que se tornam um divisor de águas para a mobilização de saberes e fazeres relacionados às suas regências, que foram permitindo desvelar especificidades locais da realidade por meio das observações que fizeram do ambiente escolar.

À medida que vão entretecendo um jogo complexo de significação da experiência construída pelo estágio, as estudantes vão compondo um repertório de saberes dos acontecimentos que foram 
possíveis de serem capturados, construídos e refletidos durante os encontros formativos nas escolas. Isso se dá, pelo fato de que “o que é re-ssignificado pela narrativa é o que já foi pré-significado no nível do agir humano” (RICOEUR, 2010, p. 138). Isso, de certa forma, foi conduzindo a compreensão que tivemos das participantes da pesquisa ao nos dizerem acerca do narrado. Elas relataram que construíram saberes e conhecimentos no estágio, por mediação das interações com as professoras da Educação Infantil, com as crianças e, em muitos casos, com os outros agentes educativos que transitavam e faziam parte da instituição educativa.

Em suma, a tessitura narrativa dos processos de aprendizagem em que a formação inicial docente se configurou, nos moldes da escrita nos diários e concretizados como dispositivos de pesquisa-formação por meio da experiência do estágio, trouxe-nos um modo outro de pensar na potencialidade do saber-fazer-dizer os saberes e conhecimentos dos processos formativos construídos narrativamente pela tomada de consciência que reflexivamente construíram as participantes da pesquisa, (re)atualizando seu repertório de conhecimentos e se apropriando de outros tantos. Contexto no qual também nos situamos a partir de uma abordagem narrativa (auto)biográfica.

Reafirmamos a importância do acompanhamento das estagiárias no cotidiano das escolas pelos supervisores da área/disciplina e das atividades realizadas. Essa experiência como professores formadores permitiu a construção de uma diversidade de saberes e conhecimentos para nós e para as estagiárias, como foi revelado em suas narrativas, compartilhadas conosco e aqui apresentadas.

\section{Considerações Finais}

Cabe à formação do pedagogo o cumprimento de uma função social, política e compromissada que se baseie nos princípios emancipatórios de uma aprendizagem substancial para que o licenciando exerça seu papel como pessoa e profissional na educação da infância e de outras tantas etapas, níveis ou modalidades de ensino em que poderá atuar.

Por meio da pesquisa com as estudantes estagiárias em formação inicial no curso de Pedagogia, urge nos questionarmos: Quais as implicações da tessitura da aprendizagem narrativa tecidas no contexto do Estágio Supervisionado na formação inicial docente?

A aprendizagem narrativa é construída pelos sujeitos à luz dos papéis pessoais e reflexivos que tecem e nos quais se envolvem, entremeados por outros tantos contextos, como os da formação universitária, socioprofissional e cultural, nos quais estão imersos e que vão se entranhando e trazendo profundas implicações em suas tessituras narrativas. 
No contexto da pesquisa-formação que realizamos com estudantes do curso de Pedagogia, estagiárias no Estágio Supervisionado em Educação Infantil, a narrativa da aprendizagem que aludem em suas escritas dão pistas para pensarmos como realizamos o nosso trabalho de formadores e como

podemos sinalizar outras reflexões do ponto de vista da pesquisa e da formação inicial e profissional de professores pedagogos.

A mediação do professor supervisor de estágio contribui, potencialmente, para o desenvolvimento das disciplinas/atividades de estágio bem como das orientações propostas por elas em consonância com o nosso olhar, e para as perspectivas de que, juntos, possamos conseguir alcançar e perceber todo esse movimento formativo.

O Estágio Supervisionado na Educação Infantil se mostrou uma experiência formadora que poderá carregar marcas fundamentais que acompanharão as estudantes em formação inicial, podendo direcioná-las na escolha da etapa de ensino em que atuarão, o que determinará, em muitos casos, os percursos de determinadas experiências futuras em múltiplos espaços-tempos da profissão.

A legitimidade da narrativa da formação inicial docente nos cursos de licenciaturas representa uma potencialidade balizadora dos percursos formativos e de uma reflexividade transformadora e (auto)formadora em que se inscrevem tanto as estudantes universitárias quanto os professores formadores, a nos situamos nesse contexto, pois passamos a ver como o pensado se materializa e se transforma em construção do conhecimento pela ação de narrar os acontecimentos trilhados no Estágio Supervisionado.

Portanto, significar os percursos de formação na aprendizagem narrativa é um modo outro de concretizarmos a potencialidade que a narração traz para o sujeito em processo de aprender a ser professor. Essa prática possibilita aliar teoria-prática às experiências formativas que se produzem no cotidiano das instituições educativas e nas múltiplas relações estabelecidas com os sujeitos nas dinâmicas institucionais, pessoais e organizacionais que concebem o saber, fazer e refletir, antes, durante e depois das atividades de estágio. Dessa forma, a narrativa ganha contornos e visibilidade de uma prática emancipatória no contexto da formação inicial e permanente de professores.

\section{Referências}

ABRAHÃO, M. H. M. B. Intencionalidade, reflexividade, experiência e identidade em pesquisa (auto)biográfica: dimensões epistemo-empíricas em narrativas de formação In.: BRAGANÇA, I. F. 
de S.; ABRRAhÃO, M. H. M. B.; FERREIRA, M. S. (Orgs.). Perspectivas epistêmicometodológicas da pesquisa (auto)biográfica. Curitiba: CRV, 2016. p. 29-50.

ALMEIDA, M. I.; PIMENTA, S. G. Centralidade do estágio em cursos de Didática nas licenciaturas: rupturas e ressignificações. In.: ALMEIDA, M. I.; PIMENTA, S. G. Estágios supervisionados na formação docente: educação básica e educação de jovens e adultos. São Paulo: Cortez, 2014. p.1540 .

ALVES, N. Cultura e cotidiano escolar. Revista Brasileira de Educação. n. 23, Rio de Janeiro. Maio/Ago. 2003. p. 62-74. Disponível em: https://www.scielo.br/scielo.php?pid=S141324782003000200005\&script=sci_arttext. Acesso em: 17 maio 2020.

BAKHTIN, M. Para uma filosofia do ato responsável. Tradução aos cuidados de Valdemir Miotello \& Carlos Alberto Faraco. 3. ed. São Carlos: Pedro \& João Editores, 2017.

BENJAMIN, W. O narrador. In.: BENJAMIN, W. Magia e técnica, arte e política: ensaios sobre literatura e história da cultura. Tradução: Sérgio Paulo Rouanet; Prefácio Jeanne Marie Gagnebin. 8. ed. São Paulo: Brasiliense, 2012. p. 213-240.

BRAGANÇA, I. F. de S. Pesquisa-formação narrativa (auto)biográfica: trajetórias e tessituras teórico-metodológicas. In.: ABRAHÃO, M. H; M. B.; CUNHA, J. L. da; BÔAS, L. V. (Orgs). Pesquisa narrativa (auto)biográfica: diálogos epistêmico-metodológicos. Curitiba: CRV, 2018. p. 65-81.

CRUZ, S. H. V. A formação inicial e continuada e a profissionalidade específica dos docentes que atuam na educação infantil. In.: FRADE, I. C. da S. [et al] (Orgs.). Convergências e tensões no campo da formação e do trabalho docente. Belo Horizonte: Autêntica, 2010. p. 361-369.

GOODSON, I. F. Currículo, narrativa pessoal e futuro social. Tradutor: Henrique Carvalho Calado; Revisão da tradução: Maria Inês Petrucci-Rosa e José Pereira de Queiroz. Campinas: Editora da Unicamp, 2019.

IMBERNÓN, F. Qualidade do ensino e formação do professorado: uma mudança necessária. São Paulo: Cortez, 2016.

JOSSO, M. C. Experiências de vida e formação. Tradução de José Cláudio, Júlia Ferreira; Revisão Maria da Conceição Passeggi, Marie-Christine Josso. 2. ed. rev. e ampl. Natal, RN: EDUFRN; São Paulo: Paulus, 2010.

MOTTA, T. da C.; BRAGANÇA, I. F. de S. Pesquisa-formação: uma opção teórico-metodológica de abordagem narrativa (auto)biográfica. Artes de dizerfazerdizer os saberes da experiência. Revista Brasileira de Pesquisa (Auto)Biográfica, Salvador, v.04, n.12, p.1034-1049, set./dez. 2019. Disponível em: https://www.revistas.uneb.br/index.php/rbpab/article/view/6191. Acesso em: 24 maio 2020.

OLIVEIRA, I. B. de. O currículo como criação cotidiana. Petrópolis: DP et alii; Rio de Janeiro: FAPERJ, 2012. 
RICOEUR, P. A memória, a história, o esquecimento. Tradução Alain François [et al]. Campinas: Editora da Unicamp, 2007.

RICOEUR, P. Tempo e narrativa. Tradução Claudia Berliner. Revisão da tradução Márcia Valéria Martinez de Aguiar. São Paulo: Martins Fontes, 2010.

\section{(c) (†) (8)} CommonsAttribution-NonCommercial 4.0 International (CC BY-NC-SA 4.0)

Recebido em: 18/04/2021

Aprovado em: 06/10/2021 